\title{
Editorial
}

\section{Nanostructured Materials for Rechargeable Lithium Batteries}

\author{
$\mathrm{Pu}$ Chen ${ }^{*}$ and Xianwen $\mathrm{Kan}^{\S}$ \\ Department of Chemical Engineering, University of Waterloo, Waterloo, Ontario, N2L 3G1, Canada \\ ${ }^{\S}$ Guest Editor
}

Energy and environment are two most challenging issues faced by our society today. With an ever increasing demand for oil, depletion of renewable fuel source, and dramatic climate change caused by $\mathrm{CO}_{2}$ emission, there is an urgent need for alternative energy source that is not based on fossil fuel. Consequently, wind, solar and wave generated energy has become heavily pursued; but to work with the grid, these forms of energy have to be stored and converted according to the electricity demand and scheduling. Batteries, especially rechargeable ones, are one of the primary energy storage and conversion systems. Research in batteries has gained tremendous speed recently, not only for large scale energy storage but also for power demand in a variety of electronic devices, such as cell phones, laptops, and all kinds of power tools. It is necessary to develop renewable, low-cost, and environmentally friendly energy conversion and storage systems, to replace much of the existing technology.

*Address correspondence to this author at the Department of Chemical Engineering, University of Waterloo, 200 University Avenue West, Waterloo, Ontario, N2L 3G1, Canada; Tel: (519) 888-4567x35586; Fax: (519) 746-4979; E-mail: p4chen@uwaterloo.ca
Among many forms of batteries, the rechargeable lithium battery has become favorite because of its features in high energy density, long cycle life, and abuse-tolerant characteristic. Still there is much to be learnt and to improve. The performance of rechargeable lithium batteries strongly depends on the structures and properties of battery materials used, especially in their specific capacity, electrochemical potential, energy and power density, and cyclability. Structural improvements include size and shape modification by employing various physical and chemical approaches. In particular, nanostructured materials represent one of the most promising as this approach can effectively contribute to a decrease in the path length for lithium ion transport, reduction in internal transfer resistance, and an increase in surface area for electrochemical reactions. The design and engineering of novel nanostructured materials for rechargeable lithium batteries have become one of the most sought after strategies for the battery research and development. The objective of this special issue is to survey the current research and development of rechargeable lithium batteries and in particular, the materials used in preparing the cathode and anode for enhanced battery performance.

(C) Chen and Kan; Licensee Bentham Open.

This is an open access article licensed under the terms of the Creative Commons Attribution Non-Commercial License (http://creativecommons.org/licenses/by-nc/3.0/) which permits unrestricted, non-commercial use, distribution and reproduction in any medium, provided the work is properly cited. 